\title{
Pulmonary aspiration associated with supraglottic airways: Proseal laryngeal mask airway and I-Gel ${ }^{\mathrm{TM}}$
}

\author{
Yoon-Hee Kim \\ Department of Anesthesiology and Pain Medicine, Chungnam National University School of Medicine, Daejeon, Korea
}

Supraglottic airways (SGAs) are increasingly used by SGA friendly users in patients who are traditionally assumed to be at an increased risk for aspiration. For instance, at first, its use was controversial, its airtight seal and the absence of gastric aspiration with the supraglottic airway during laparoscopic surgery was shown throughout "conventional" positive ventilation $[1,2]$.

The evidence to date suggests that pulmonary aspiration associated with the supraglottic airway is rare and has an incidence comparable to that of outpatient anesthesia with the face mask and endotracheal tube [3]. However, in principal, supraglottic airways do not prevent gastric aspiration as reliably as tracheal intubaton does.

The insertion of the SGA has been reported to increase the esophageal motility and to reduce the lower esophageal sphincter barrier pressure. A possible mechanism for this situation is that the distension of pharynx induced by large inflated cuff of the SGA trigger the pharyngo-esophago-gastric reflex [4]. When conscious, this reflex will facilitate swallowing.

SGA with features, such as airtight sealing, separate access to the gastrointestinal and respiratory tracts and esophageal drainage tube improve the safety and efficacy of positive pressure ventilation, provide a means of gastric suctioning, reduce the gastric distension, and the risk of pulmonary aspiration.

There are now several supraglottic airways marketed that are specifically designed to reduce the risk of aspiration. Five devices are designed to separate the respiratory and gastrointestinal tracts: the I-Gel ${ }^{\mathrm{TM}}$ (Intersurgical Ltd, Wokingham, Berkshire, UK), laryngeal tube suction mark II (LTS II) and its disposable version (LTS-D) (VBM GmbH, Sulz, Germany), the proseal laryngeal mask airway, the recently introduced laryngeal mask airway Supreme (Intavent Orthofix, Maidenhead, UK), and the streamlined liner of the pharyngeal airway (Teleflex Medical, High Wycombe, UK, SLIPA). The device SLIPA is designed to prevent aspiration through its large hollow chamber that can store up to $50 \mathrm{ml}$ of regurgitant gastric fluid [5].

In this edition of Korean Journal of Anesthesiology, Jeon et al. [6] presented a clinical study on 30 patients undergoing laparoscopic gynecologic surgery with either a Proseal laryngeal mask airway or an $\mathrm{I}-\mathrm{Gel}^{\mathrm{TM}}$ to secure the airway. The study showed that there was no significant difference in the leak fraction between the two airways. The authors concluded that $\mathrm{I}-\mathrm{Gel}^{\mathrm{TM}}$ is a reasonable alternative to the Proseal laryngeal mask airway for controlled ventilation during laparoscopic gynecological surgery.

Proseal laryngeal mask airway and I-Gel ${ }^{\mathrm{TM}}$ are second generation SGA that has high esophageal sealing pressure and esophageal drainage tube, effective in preventing gastric aspiration. The use of the Proseal laryngeal mask airway since been reported in a number of clinical situations, including elective laparoscopic surgery and even in patients ventilated in the prone position $[7,8]$. In addition to the use for planned anesthesia, current guidelines also recommend Proseal laryngeal mask airway as an alternative to tracheal intubation during cardiopulmonary resuscitation [9]. In a fresh cadaver model, where the esophagus was filled with fluid increase pressure, Proseal laryngeal mask airway showed complete protection during esophageal regurgitation when esophageal drainage tube was patent [10].

Corresponding author: Yoon-Hee Kim, M.D., Ph.D., Department of Anesthesiology and Pain Medicine, Chungnam National University School of Medicine, Munhwa-ro, Jung-gu, Daejeon 301-721, Korea. Tel: 82-42-280-7840, Fax: 82-42-280-7968, E-mail: yhkim040404@gmail.com (ㄷ) This is an open-access article distributed under the terms of the Creative Commons Attribution Non-Commercial License (http:// creativecommons.org/licenses/by-nc/3.0/), which permits unrestricted non-commercial use, distribution, and reproduction in any medium, provided the original work is properly cited. 
$\mathrm{I}-\mathrm{Gel}^{\mathrm{TM}}$ is a noninflatable supraglottic airway made up of a thermoplastic elastomer (styrene ethylene butadiene styrene) with a soft durometer and gel-like feel. Supraglottic airways with inflatable cuff are effective sealing the airway, but inflation itself may cause the position of the device to change. On the other hand, a noninflatable I-Gel ${ }^{\mathrm{TM}}$ has potential advantages, including easier insertion, minimal tissue compression, and reduced risk of undesired changes of position after insertion [11]. A systematic investigation of the sealing efficacy with the $\mathrm{I}_{-} \mathrm{Gel}^{\mathrm{TM}}$ has not been reported yet. Gibbison et al. [5] reported a case series describing the cases of regurgitation with successful drainage through the gastric drainage tube and one aspiration with inadequate drainage out of 280 total patients. I-Gel ${ }^{\mathrm{TM}}$ provided leak pressures in the upper range of comparable supraglottic airway, but not as high as the Proseal Laryngeal Mask [12]. Schmidbauer et al. [10] suggest that at high esophageal pressures, the esophageal seal provided by the cuff of the laryngeal mask airway (Classic laryngeal mask airway or Proseal laryngeal mask airway) is superior to the esophageal seal created by the pre-shaped plastic mask body of I-Gel ${ }^{\mathrm{TM}}$.

In addition, the esophageal drainage tube of the $\mathrm{I}-\mathrm{Gel}^{\mathrm{TM}}(12 \mathrm{~F}$ for size 3 and 4 and $14 \mathrm{~F}$ for size 5) is smaller than for the Proseal laryngeal mask ( $16 \mathrm{~F}$ in a size 4 Proseal laryngeal mask). Also, the distal end of $\mathrm{I}-\mathrm{Gel}^{\mathrm{TM}}$ is deformable, inefficiently draining regurgitant fluid from the smaller, deformable esophageal drainage tube [5]. In a magnetic resonance imaging study by Russo et al. [13], Supreme laryngeal mask airway, a disposable Proseal laryngeal mask airway, protruded the upper esophageal sphincter deeper than $\mathrm{I}_{-} \mathrm{Ge}^{\mathrm{TM}}$. The study suggesting that Proseal laryngeal mask airway is more effective than $\mathrm{I}-\mathrm{Gel}^{\mathrm{TM}}$ in pulmonary aspiration. However, because correct positioning of SGA is important in protecting gastric aspiration, I-Gel ${ }^{\mathrm{TM}}$ with good position stability may have superiority over Proseal laryngeal mask, regarding this matter. A further comparison between the two is needed. Pulmonary aspiration during anesthesia was affected more often by inappropriate use rather than the inherent defect of the airway device itself. SGAs have attractive features, which include noninvasiveness, easiness and simplicity. With further revolution and advancements concern regarding risk of pulmonary aspiration is soon to take a turn for the better.

\section{References}

1. Maltby JR, Beriault MT, Watson NC, Liepert D, Fick GH. The LMA-ProSeal is an effective alternative to tracheal intubation for laparoscopic cholecystectomy. Can J Anaesth 2002; 49: 857-62.

2. Maltby JR, Beriault MT, Watson NC, Liepert DJ, Fick GH. LMAClassic and LMA-ProSeal are effective alternatives to endotracheal intubation for gynecologic laparoscopy. Can J Anaesth 2003; 50: 71-7.

3. Brimacombe JR, Berry A. The incidence of aspiration associated with the laryngeal mask airway: a meta-analysis of published literature. J Clin Anesth 1995; 7: 297-305.

4. Barker P, Langton JA, Murphy PJ, Rowbotham DJ. Regurgitation of gastric contents during general anaesthesia using the laryngeal mask airway. Br J Anaesth 1992; 69: 314-5.

5. Gibbison B, Cook TM, Seller C. Case series: Protection from aspiration and failure of protection from aspiration with the i-gel airway. Br J Anaesth 2008; 100: 415-7.

6. Jeon WJ, Cho SY, Baek SJ, Kim KH. Comparison of the Proseal LMA and intersurgical I-gel during gynecological laparoscopy. Korean J Anesthesiol 2012; 63: 510-4.

7. Miller DM, Camporota L. Advantages of ProSeal and SLIPA airways over tracheal tubes for gynecological laparoscopies. Can J Anaesth 2006; 53: 188-93.

8. Brimacombe JR, Wenzel V, Keller C. The proseal laryngeal mask airway in prone patients: a retrospective audit of 245 patients. Anaesth Intensive Care 2007; 35: 222-5.

9. Soar J, Deakin CD, Nolan JP, Abbas G, Alfonzo A, Handley AJ, et al. European Resuscitation Council guidelines for resuscitation 2005. Section 7. Cardiac arrest in special circumstances. Resuscitation 2005; 67 Suppl 1: S135-70.

10. Schmidbauer W, Bercker S, Volk T, Bogusch G, Mager G, Kerner T. Oesophageal seal of the novel supralaryngeal airway device I-Gel in comparison with the laryngeal mask airways Classic and ProSeal using a cadaver model. Br J Anaesth 2009; 102: 135-9.

11. Levitan RM, Kinkle WC. Initial anatomic investigations of the I-gel airway: a novel supraglottic airway without inflatable cuff. Anaesthesia 2005; 60: 1022-6.

12. Brimacombe J, Keller C, Brimacombe L. A comparison of the laryngeal mask airway ProSeal and the laryngeal tube airway in paralyzed anesthetized adult patients undergoing pressure-controlled ventilation. Anesth Analg 2002; 95: 770-6.

13. Russo SG, Cremer S, Eich C, Jipp M, Cohnen J, Strack M, et al. Magnetic resonance imaging study of the in vivo position of the extraglottic airway devices i-gel ${ }^{\mathrm{TM}}$ and LMA-Supreme ${ }^{\mathrm{TM}}$ in anaesthetized human volunteers. Br J Anaesth 2012; 109: 996-1004. 